\title{
Swimming behaviour of marine bivalve larvae in a flume boundary-layer flow: evidence for near-bottom confinement
}

\author{
Per R. Jonsson ${ }^{1}$, Carl André ${ }^{2}$, Mats Lindegarth ${ }^{1}$ \\ ${ }^{1}$ Tjärnö Marine Biological Laboratory, Pl. 2781, S-452 00 Strömstad, Sweden \\ ${ }^{2}$ Department of Zoology, Stockholm University, S-106 91 Stockholm, Sweden
}

\begin{abstract}
The swimming behaviour of settling larvae of the bivalve Cerastoderma edule (L.) was studied in still water and in a flume boundary-layer flow. In still water and slow flow the larvae swam upward in helices with high directionality, which is interpreted as morphological geotaxis. By reducing velar propulsion larvae regularly descended towards the bottom due to gravity. In moderate and fast flow ( 5 to $10 \mathrm{~cm} \mathrm{~s}^{-1}$ ) the larvae became confined to the viscous sublayer, where they slowly drifted in the streamwise direction at 0.45 to $1.6 \mathrm{~mm} \mathrm{~s}^{-1}$, less than $1 \mathrm{~mm}$ above the sediment surface, periodically making contact with the bottom. At flow velocities exceeding $15 \mathrm{~cm} \mathrm{~s}^{-1}$ the steady near-bottom drift changed to bed-load transport of tumbling larvae with high probability of resuspension. Based on kinematic and force analysis of swimming behaviour we suggest that boundary-shear induced torque restricts the settling larvae to the viscous sublayer. This near-bottom confinement may explain how habitat selection in benthic bivalves is realized under natural flow regimes.
\end{abstract}

\section{INTRODUCTION}

Populations of sessile, benthic invertebrates tend to be clumped in time and space on marine bottoms (Petersen 1918, Thorson 1966). Non-random patterns of species with a free swimming, larval phase may be attributed to either differences in settling intensity or differential mortality among juveniles (Keough \& Downes 1982, Luckenbach 1984). The processes that affect settling intensity and juvenile mortality are very different and knowledge of their relative importance is necessary to improve models of how populations of sessile invertebrates are temporally and spatially distributed (Underwood \& Fairweather 1989).

Settling intensity of larvae in a given area is a function of the flux of competent larvae and the probability of settling and metamorphosis. Many experimental studies have shown that the settling probability of invertebrate larvae may be strongly affected by properties of the substratum, mainly through chemical cues (e.g. Wilson 1968, reviewed in Butman 1987). These substratum-specific responses have often been suggested to explain observed, non-random settle- ment patterns. However, most of the experiments that have tested substratum selection have been performed in still water and at small spatial scales, allowing larvae to search for suitable substrata by active larval locomotion. Locomotion in marine invertebrate larvae is accomplished either by muscular (e.g. nauplii, ascidian tadpoles) or by ciliary propulsion (e.g. planulae, trochophora, veligers) with typical swimming speeds between 1 and $10 \mathrm{~mm} \mathrm{~s}^{-1}$ (reviewed in Chia et al. 1984). Accordingly, some authors have questioned how substratum selection can be exercised in natural environments characterized by flows often orders of magnitude faster than larval locomotion, and with highly patchy distributions of preferred substrata (Moore 1975, Butman 1987). It is now recognized that hydrodynamical forces due to the flow of water over the bottom may influence settlement intensity in various ways without having to invoke active larval choice (Eckman 1983, 1990). Heterogeneous settlement patterns are thus not a sufficient condition to demonstrate substratum selection by larvae and it remains to explain the relative importance of and the interactions between hydrodynamic processes and larval behaviour. 
From small-scale flume experiments it has been shown that larvae can actively choose among different bottom substrata, despite larval swimming velocities of only some $\mathrm{mm} \mathrm{s}^{-1}$ (Butman et al. 1988, Pawlik et al. 1991). However, how this habitat selection in flowing water is accomplished and how larval behaviour interacts with water flow has only recently received attention (Eckman et al. 1990, Pawlik et al. 1991).

The purpose of the present study was to observe and analyze the behaviour of free-swimming bivalve larvae Cerastoderma edule during settlement on a sedimentary bottom subjected to water flow. Swimming behaviour of bivalve larvae in still water has been investigated previously in several studies, often in order to explain oriented responses to environmental cues (e.g. Bayne 1964, Mann \& Wolf 1983, Mann et al. 1991). However, it is uncertain how swimming patterns in still water relate to motion in flowing water where shear forces may influence the significance of behaviour (Pawlik et al. 1991). In this work we describe the basic swimming pattern of $C$. edule larvae in still water by applying a kinematic analysis which allows us to infer the forces acting on the larva. Knowledge on these forces is then used to interpret the observations from a series of flume experiments which tested the ability of larvae to explore the sediment substratum prior to settlement.

\section{MATERIALS AND METHODS}

Study organism. Cerastoderma edule (Linnaeus, 1758), formerly Cardium edule, is an infaunal bivalve living in marine, shallow sediments along the Atlantic coast from West Africa to Norway. In both muddy and sandy sediments $C$. edule is often a dominant suspension feeder and can reach densities of several hundreds of adults per $\mathrm{m}^{2}$ (Beukema 1976, Möller \& Rosenberg 1983). C. edule releases eggs and sperm into the water and the larval development is planktotrophic, lasting 2 to $4 \mathrm{wk}$. The newly hatched veliger measures ca $120 \mu \mathrm{m}$ and grows to a size of ca $280 \mu \mathrm{m}$ at the time of settlement. Along the Swedish west coast peak settlement of larvae occurs from late June to July (Möller \& Rosenberg 1983, André \& Rosenberg 1991).

Rearing of larvae. On 2 occasions (30 May and 15 June 1990) about 40 adult Cerastoderma edule were collected from muddy sediment bottoms ca $2 \mathrm{~km}$ from Tjärnö Marine Biological Laboratory, Sweden. Each individual was kept separately in disposable plastic mugs $(150 \mathrm{ml})$ filled with filtered (Millipore CWSS01TP3, ca $0.2 \mu \mathrm{m})$ surface seawater $(26 \% \mathrm{~S}$, $19{ }^{\circ} \mathrm{C}$ ). Within $24 \mathrm{~h}$, about $20 \%$ of the individuals spawned. Eggs from all spawned females were pooled and suspended in filtered seawater in 101 glass carboys. The discharge of sperm from every spawned male was first diluted in $200 \mathrm{ml}$ filtered seawater and $2 \mathrm{ml}$ of this suspension from each male were then added to the carboys containing eggs, and mixed by gentle stirring for $1 \mathrm{~min}$. The culture was left to incubate at $15^{\circ} \mathrm{C}$ for 2 to $3 \mathrm{~d}$. Each day for the following $4 \mathrm{~d}$, hatched larvae were siphoned to new glass bottles, leaving undeveloped embryos on the bottom. The larvae were sieved, rinsed and transferred to fresh filtered seawater, and fed ca $7.5 \times 10^{4}$ cells $\mathrm{ml}^{-1}$ of Isochrysis galbana every $2 \mathrm{~d}$. After 17 to $21 \mathrm{~d}$ from fertilization, at a size of ca $280 \mu \mathrm{m}$, the larvae had a well developed foot (pediveliger stage) and were competent to settle.

Fluorescent labelling. The purpose of the present study was to observe and analyze the behaviour of bivalve larvae during settlement on a sedimentary bottom subjected to water flow. The small size of most marine, bivalve larvae (ca 200 to $400 \mu \mathrm{m}$ ) makes it difficult to follow individual larvae in flowing water on a macroscopical scale. To visualize larvae, we labelled competent (larvae able to settle; defined as pediveliger stage) laboratory-reared larvae with fluorescent pigment particles (Radglo, Radiant Color N.V., Houthalen, Belgium). The pigment (equivalent spherical diameter of 2 to $10 \mu \mathrm{m}$ ) was suspended in seawater with a small droplet of detergent, and this stock suspension was added to the bottles containing larvae to yield a final concentration of $10^{5}$ particles $\mathrm{ml}^{-1}$. Pigment particles were readily ingested by the larvae and after $2 \mathrm{~h}$ the gut region was abundant with fluorescent pigment. Upon illumination in blue light individual, fluorescent larvae were visible from about $0.5 \mathrm{~m}$. A detailed description of the labelling procedure can be found in Lindegarth et al. (1991).

Flume. All experiments with fluorescently labelled larvae of Cerastoderma edule in flowing water were performed in a laboratory flume tank (see Vogel 1981). The flume has a length, width and depth of 3.5 , 0.5 and $0.4 \mathrm{~m}$ respectively. The working section is $0.4 \times 0.5 \mathrm{~m}$ and located $2.4 \mathrm{~m}$ downstream of the inlet. Water flow is driven by 2 propellers and the water is recircled between the outlet and inlet by a PVC tube (0.32 $\mathrm{m}$ diameter), making a closed circuit. Two collimators (10 $\mathrm{mm}$ grid diameter) in series served to rectify flow when water entered the flume tank. A variable speed motor $(0.75 \mathrm{~kW})$ allowed control of the flow speed. Inspection with injected dye showed that the flume produced a steady and unidirectional flow at the working section. Velocity profiles from $2 \mathrm{~mm}$ above the bottom and upwards were measured with a heated thermistor probe (Vogel 1981) where flow velocity at $250 \mathrm{~mm}$ above the bottom was considered to represent free-stream velocity, $U_{\infty}$. Measurements very close to the bottom 
were not possible due to limitations of the spatial resolution of the thermistor, and velocity profiles from 0.05 to $3 \mathrm{~mm}$ above the sediment were constructed from video recordings of the near-bottom flow from the side of the flume. Recorded sequences were played frame by frame and local flow velocity was measured by tracing particles carried in the water flow (see below for a description of recording equipment). The linear part of the near-bottom velocity gradient was assumed to represent the viscous sublayer characterized by laminar flow. This was supported by direct observation of the 1-dimensional trajectories of particles in this region. For each flow at least 20 particles were measured to construct the velocity profile, and the slope of the measured velocity gradient was estimated by linear regression.

A marked boundary-layer developed above the working section with a logarithmic velocity profile extending to ca $5 \mathrm{~cm}$ above the bottom (Fig. 1). Measured velocity profiles were similar along the streamwise direction at the working section with shear velocity $(u \cdot)$ estimated at the front and rear of the working section as $0.38 \pm 0.021 \mathrm{~cm} \mathrm{~s}^{-1}$ and $0.35 \pm$ $0.0087 \mathrm{~cm} \mathrm{~s}^{-1}$ respectively (mean $\pm \mathrm{SE} ; \mathrm{p}>0.05$, $\left.t=1.4, \mathrm{df}=2 ; U_{\infty}=10 \mathrm{~cm} \mathrm{~s}^{-1}\right)$. Although the flume does not generate an equilibrium boundary-layer at the water depth used $(0.35 \mathrm{~m})$ we consider the boundary-layer thickness to be adequate for the study of larval behaviour in a thin (ca $10 \mathrm{~mm}$ ) layer close to the sediment surface. Boundary-layers created by the flume walls were measured for all used flow speeds to determine the effective width of the working section

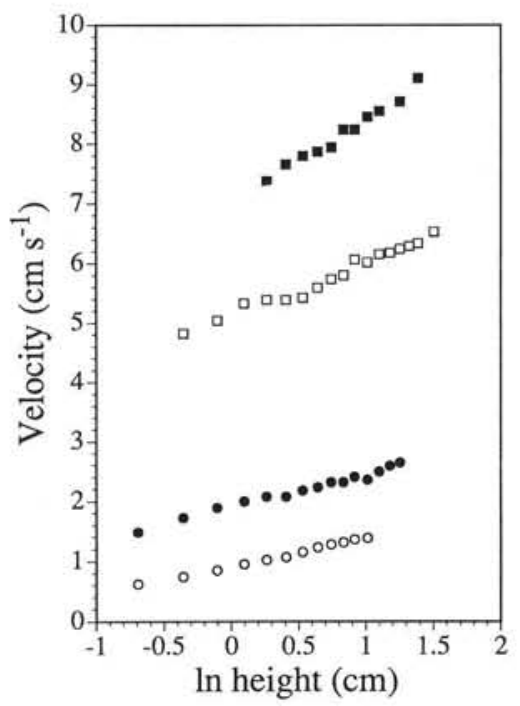

Fig. 1. Flow velocity as a function of the natural logarithm of the height over the bottom for 4 different flows; (o) $U_{\infty}=$ $2 \mathrm{~cm} \mathrm{~s}^{-1}$, (•) $U_{\infty}=5 \mathrm{~cm} \mathrm{~s}^{-1}$, (ㅁ) $U_{\infty}=10 \mathrm{~cm} \mathrm{~s}^{-1}$, (घ) $U_{\infty}=$ $15 \mathrm{~cm} \mathrm{~s}^{-1}$ and all observations and measurements were limited to this area.

The average boundary shear stress due to turbulence is described by the boundary shear velocity, $u$. (Schlichting 1979). Shear velocity was calculated for all studied flows $\left(U_{\infty}=2,5,10\right.$ and $\left.15 \mathrm{~cm} \mathrm{~s}^{-1}\right)$ from the logarithmic part of the velocity profile, shown in Fig. 1, by fitting the velocity measurements to the equation for 'the law of the wall' for smooth surfaces given by:

$$
U(z)=\frac{u *}{k} \ln \frac{z}{z_{0}}
$$

where $U(z)=$ mean downstream velocity at height $z$ above the bottom; $z_{0}=$ roughness height; and $k=$ Karman's constant (0.4). Estimates of $u$, were then used to calculate the roughness Reynolds number, Re*:

$$
R e *=\frac{u_{*} k_{s}}{V}
$$

where $k_{s}=$ bed roughness scale (ca $170 \mu \mathrm{m}$; mean grain diameter in our experiments); and $v=$ kinematic viscosity of seawater. At all studied flows Re. was below 4 and our studied boundary layers are characterized as smooth turbulent (Nowell \& Jumars 1984).

Swimming behaviour in still water. The swimming behaviour of Cerastoderma edule in still water was observed in a small aquarium $(10 \times 10 \times 2.5 \mathrm{~cm})$ through a horizontally mounted dissecting microscope (Wild M5A, $12-25 \times$ ) equipped with a video camera (Panasonic CCD-F10). The video-recorder (Panasonic NV-180) allowed a time resolution of $40 \mathrm{~ms}$ between frames, and larval trajectories were traced, frame by frame, on a transparent film covering the monitor screen. The tracings represent 2-dimensional projections of the helical swimming trajectories, and swimming, sinking and rotational velocities in 3 dimensions were estimated using kinematic analysis of helical motion.

An excellent and thorough kinematic analysis of helical motion is provided by Crenshaw $(1989 \mathrm{a}, \mathrm{b})$ where it is shown how the pitch $(p)$, radius $(r)$ and angular velocity $(\gamma)$ of a helical trajectory can be expressed in terms of the organism's translational and rotational velocities (Fig. 2). With one translational $(U)$ and 2 rotational $\left(\omega_{1}=\right.$ roll rotation and $\omega_{2}=$ pitch rotation; note that the terms pitch rotation and pitch of the helix are different) degrees of freedom, the relations are

$$
\begin{aligned}
& p=\frac{2 \pi U \omega_{1}}{\omega_{1}^{2}+\omega_{2}^{2}} \\
& r=\frac{U \omega_{2}}{\omega_{1}^{2}+\omega_{2}^{2}} \\
& \gamma=\sqrt{\omega_{1}^{2}+\omega_{2}^{2}}
\end{aligned}
$$


a

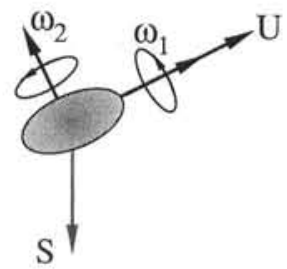

b

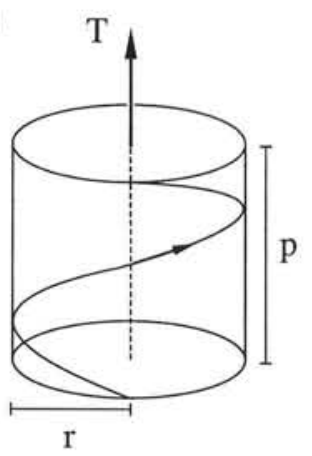

Fig. 2. Schematic drawing of the velocity components of a swimming larvae and the resulting helical path. (a) Swimming larva with translational velocity $U$, roll and pitch rotational velocities $\omega_{1}$ and $\omega_{2}$, and gravitational sinking velocity $S$. (b) One revolution of a helical path with radius $r$ and pitch $p$ resulting in the net ascent velocity $T$

These equations were used to estimate $U_{1} \omega_{1}$ and $\omega_{2}$ from 2-dimensional measurements of $p, r$ and $\gamma$. This procedure assumes that the axis of the helical path is always vertical; the validity of this assumption is discussed below. The observed trajectory is the resultant of the propulsive and the gravitational forces, and the relative magnitudes of these forces will affect the appearance of the helical path. To calculate the true rotational velocities $\omega_{1}$ and $\omega_{2}$ generated by the larva, a pitch $\left(p^{\prime}\right)$ corrected for gravitational sinking was calculated from the observed pitch of the helix $(p)$ as

$$
p^{\prime}= \pm p+\frac{2 \pi S}{\gamma}
$$

where $S=$ sinking velocity of non-swimming larvae. The sign of $p$ is negative if the larva is sinking.

Swimming behaviour in shear flow. The behaviour and movement of the fluorescently labelled larvae in the flume tank were first observed macroscopically at 4 flow velocities $\left(U_{\infty}=0,2,5\right.$, and $\left.10 \mathrm{~cm} \mathrm{~s}^{-1}\right)$. The slow drift of larvae in the near-bottom flow was measured by timing individual larvae over a known distance. Larvae in flowing water $\left(U_{\infty}=0,5,10\right.$ and $15 \mathrm{~cm} \mathrm{~s}^{-1}$ ), were also video-recorded (equipment as above) from the side of the flume, perpendicular to flow direction. The flow motion, the limited field of depth and the low time resolution of the videorecorder made observations difficult and each larva could be followed for only some seconds. It was not possible to trace the trajectory of any larva with enough resolution to allow a detailed analysis of the larval motion resulting from the combination of shear flow and helical swimming behaviour. As an indication of the shear force acting on the larvae during near-bottom drift, we used the body orientation of drifting larvae, measured as the maximum acute angle between the vertical line and the velum-umbo axis of larvae when viewed along the anteriorposterior axis. From video-recorded sequences of larvae drifting above the bottom, we also measured the distance between umbo and sediment surface.

Model. In the analysis of the effect of near-bottom shear on larval swimming behaviour, helical motion was modelled using 1 translational and 2 rotational degrees of freedom following the kinematic analysis of helical motion (Eqs. 3 to 5). The trajectories for different sets of $L$ (separation distance between centres of buoyancy and gravity, see Eq. 11), swimming velocity and pitch and roll rotational velocities were solved by finite difference computer simulation. Measurements in the flume of the linear near-bottom and the overlying logarithmic velocity gradient (see Table 2 and Fig. 1) were included in the model, and at each time increment $(0.001 \mathrm{~s})$ the gravitational and viscous torques were evaluated (see Eqs. 11 \& 15). Threedimensional plots from each run were used to determine if trajectories were confined to the near-bottom region or escaped upwards.

\section{RESULTS AND DISCUSSION}

Before we attempt an analysis of the behaviour of Cerastoderma edule larvae in flowing water it is necessary to investigate the swimming patterns found in still water. A kinematic analysis of the helical swimming path provides a tool for the interpretation of observed patterns in terms of translational and rotational velocities generated by the larvae. We also present arguments for a geotaxic mechanism to explain the observed directional movement of larvae.

\section{Swimming behaviour in still water}

Larvae of Cerastoderma edule basically swim upwards in a right-hand helix with the velum up and the shell umbo pointing down. During upward swimming, the helical motion of pediveliger larvae was characterized by a mean swimming velocity of 0.91 $\mathrm{mm} \mathrm{s}^{-1}$, a net ascent speed of $0.71 \mathrm{~mm} \mathrm{~s}^{-1}$, and pitch, radius and angular velocity of the helix as shown in Table 1. Applying a kinematic analysis (Crenshaw 1989b) the helical motion can be expressed in terms of the organism's translational and rotational velocities, which are more biologically relevant. When the helical path is corrected for sinking, this yields roll and pitch rotational velocities of 3.2 and $0.56 \mathrm{rad}$ $\mathrm{s}^{-1}$ respectively (Table 1 ). Occasionally the velum is retracted and the larva rapidly sinks with an average 
Table 1. Cerastoderma edule. Parameters describing the swimming behaviour of larvae, measured from trajectories observed in still water (mean $\pm \mathrm{SD} ; \mathrm{n}=13$ for ascending and $\mathrm{n}=10$ for descending larvae)

\begin{tabular}{lcc|}
\hline & Ascending larvae & Descending larvae \\
\hline Swimming velocity $(U), \mathrm{mm} \mathrm{s}^{-1}$ & $0.91 \pm 0.31$ & $1.3 \pm 0.37$ \\
Net ascent/descent velocity $(T), \mathrm{mm} \mathrm{s}^{-1}$ & $0.71 \pm 0.44$ & $1.0 \pm 0.40$ \\
Radius of helix $(r), \mathrm{mm}$ & $0.18 \pm 0.11$ & $0.40 \pm 0.21$ \\
Pitch of helix $(p), \mathrm{mm}$ & $1.3 \pm 0.50$ & $2.9 \pm 0.85$ \\
Angular velocity of helix $(\gamma), \mathrm{rad} \mathrm{s}^{-1}$ & $3.2 \pm 1.5$ & $2.0 \pm 0.72$ \\
Roll rotation $\left(\omega_{1}\right), \mathrm{rad} \mathrm{s}^{-1}$ & $3.2 \pm 1.5$ & $1.2 \pm 0.85$ \\
Pitch rotation $\left(\omega_{2}\right), \mathrm{rad} \mathrm{s}^{-1}$ & $0.56 \pm 0.20$ & $1.3 \pm 0.83$ \\
Free fall velocity $(S), \mathrm{mm} \mathrm{s}^{-1}$ & - & $1.7 \pm 0.43$ \\
\hline
\end{tabular}

velocity of $1.7 \mathrm{~mm} \mathrm{~s}^{-1}$. A slower descent is possible by applying some upward propulsion which reduces gravitational sinking (Table 1 ). Net vertical velocity $(T)$ is a function of swimming $(U)$ and sinking $(S)$ velocities and the rotational velocities $\left(\omega_{1}\right.$ and $\left.\omega_{2}\right)$ as

$$
T=\frac{U}{\sqrt{1+\frac{\omega_{2}^{2}}{\omega_{1}^{2}}}}-S
$$

The helical swimming behaviour provides a possibility to reduce the ascent velocity or to sink through the water column without having to reduce the swimming speed through the water. This may instead be accomplished by changing the relative magnitude of the rotational velocities $\omega_{1}$ and $\omega_{2}$. Feeding currents and food capture could thus, in theory, continue independent of net vertical velocity. The estimates of swimming variables allow an analysis of the forces acting on the larva, which provides information on how net vertical velocity is regulated. The total force applied by the larva can be decomposed into 2 components, $\overrightarrow{F_{\text {drag }}}$

$$
\left|\overrightarrow{F_{\text {drag }}}\right|=6 \pi \mu a U
$$

(Happel \& Brenner 1983) which balances the hydrodynamical drag when swimming through the water ( $\mu$ = dynamic viscosity, $a=$ Stokes' radius), and a component opposing the gravitational force $(\overrightarrow{\Delta m} g)$ where $\Delta m$ represents the excess mass (difference between larval mass and the mass of the displaced seawater), and $g=$ acceleration of gravity. If the helical axis is assumed to be vertical, the 2 force components make an angle $\phi$ which is

$$
\phi=\pi-\arctan \left[\frac{\omega_{2}^{2}}{\omega_{1}^{2}}\right]
$$

(Crenshaw 1989b). Note that $\omega_{2}$ and $\omega_{1}$ in Eq. (9) are the apparent rotational velocities as calculated from observed trajectories, which are the result of helical motion and sinking velocity; translation of these into the realized $\omega_{2}$ and $\omega_{1}$ is done by use of the corrected helical pitch, $p^{\prime}$, in Eq. (6).

The total force $\left(\overrightarrow{F_{\text {tot }}}\right)$ is the vector sum of the components

$\left|\overrightarrow{F_{\text {tot }}}\right|=\sqrt{\left|\overrightarrow{F_{\text {drag }}}\right|^{2}+|\overrightarrow{\Delta m} g|^{2}-2\left|\overrightarrow{F_{\text {drag }}}\right||\overrightarrow{\Delta m} g| \cos (\phi)}$

Using the estimates of apparent $\omega_{2}$ and $\omega_{1}$ from observations of ascending Cerastoderma edule larvae and assuming a larval density of $1.1 \mathrm{~g} \mathrm{~cm}^{-3}$ (Eriksson \& Jonsson unpubl.) and a Stokes' radius of $120 \mu \mathrm{m}$, the total force generated by the velum is $5.8 \times 10^{-9} \mathrm{~N}$. In descending larvae the force components make an angle $\phi^{\prime}$ which is $\arctan \left(\omega_{2} / \omega_{1}\right)$, and the total velar force is estimated to $2.2 \times 10^{-9} \mathrm{~N}$. Thus, there is a true reduction in velar activity during decent, although almost $40 \%$ of the force still remains for the generation of velar feeding currents in spite of the net sinking rate being $60 \%$ of the free falling velocity. This possibility to regulate net movement by adjustment of rotational rather than translational velocities is analogous to the patch behaviour shown by a benthic ciliate described by Fenchel \& Jonsson (1988).

\section{Geotaxis}

Movement of Cerastoderma edule larvae is constrained along the vertical axis through upward helical swimming or downward gravitational sinking. Directed upward swimming of $C$. edule larvae continues in the absence of light, turbulence, and known chemical gradients (unpubl. obs.), and the only conceivable cue is the force of gravity. Similar observations of directed swimming have been presented for other planktonic larvae and some kind of geotaxis has been inferred (Runnström 1930, Sulkin 1973, Pires \& Woollacott 1983, Pennington \& Strathmann 1990). Geotaxis is usually considered as a true perception of the direction of gravity by means of statocyst-like mechanoreceptors. Statocysts are known from some larvae, 
e.g. gastropods (Chia et al. 1981), late larval stages of pectenid bivalves (Cragg \& Nott 1977) and decapod crustaceans (Sulkin 1984). However, many larvae do not possess statocysts, e.g. echinoderms (Pennington \& Strathmann 1990), and the function of early statocysts is still poorly documented. To explain observations of apparent geotaxis where a statocyst is absent, it has been suggested that this is a passive consequence of the interaction between gravity and some body asymmetry of the organism. These hypotheses state that body asymmetry in hydrodynamic drag (Roberts 1970) or in density distribution (Kessler 1986) may cause a non-random orientation of the body and thus directional swimming. Support for passive geotaxic mechanisms has been found for ciliates (Roberts 1970, Jonsson 1989) and for echinoderm larvae (Pennington \& Strathmann 1990).

Observations of anesthetized or fixed Cerastoderma edule larvae show that if they are perturbed from their orientation with the umbo pointing downwards, they will rapidly return to the initial orientation. The reorientation indicates that the larval body has a stable orientation, and we suggest that this is caused by the larval shell which makes the density distribution asymmetric. This is because the dorsal position of the dense calcite shell will result in greater excess density compared to the ventral velar region. The high larval density of $1.1 \mathrm{~g} \mathrm{~cm}^{-3}$ suggests that the shell indeed contributes significantly to excess density. An asymmetric density distribution will create a gravitational torque $T_{\text {grav }}$ due to the separation of the centre of gravity and the centre of buoyancy by a vector $\vec{L}$ (Fig. 3),

$$
T_{\text {grav }}=m g L \sin \Theta
$$

where $m=$ larval mass and $\Theta=$ angle between $\vec{L}$ and the gravity vector $\overrightarrow{m g}$ (Kessler 1986). The torque will tend to return the body to the stable orientation where

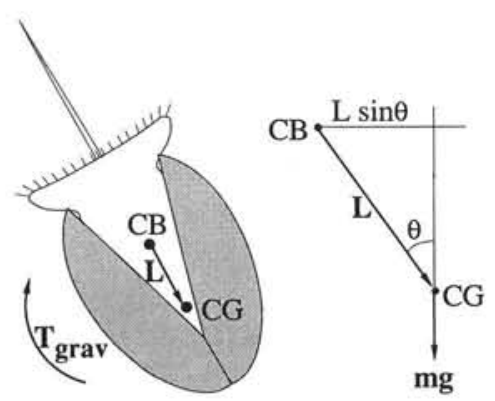

Fig. 3. Cerastoderma edule. Schematic drawing of a larva, viewed from the anterior side. It is suggested that the shelled part of the body (shaded) causes a,separation of the centres of gravity (CG) and buoyancy (CB) by a distance $L$. This leads to a gravitational torque ( $T_{\text {grav }}$ ) which is proportional to $L \sin \Theta$ as shown in the force diagram ( $m g=$ force of gravity). Note that the magnitude of $L$ is greatly exaggerated
$\vec{L}$ is in the direction of $\overrightarrow{m g}(\Theta=0)$. Now, the torque required to rotate a sphere in a viscous fluid at an angular velocity $\omega$ is

$$
T=8 \pi \mu a^{3} \omega
$$

where $\mu=$ dynamic viscosity; $a=$ sphere radius (Happel \& Brenner 1983). If the larva is assumed to be spherical with radius $a$ and having a body density $\rho(m$ $\left.=4 \pi a^{3} \rho / 3\right)$, Eqs. (11) \& (12) can be combined to

$$
\frac{\mathrm{d} \Theta}{\sin \Theta}=\frac{L \rho g}{6 \mu} \mathrm{d} t
$$

where $\mathrm{d} \Theta / \mathrm{d} t=\omega$. If the time, $\tau$, taken to reorient the larva from e.g. $\pi / 4$ to $3 \pi / 4 \mathrm{rad}$ is known, it is possible to solve for $L$ by integration of Eq. (13):

$$
\mathrm{L}=\frac{6 \mu}{\rho g \tau} \int_{3 \pi / 4}^{\pi / 4} \frac{\mathrm{d} \Theta}{\sin \Theta}
$$

Estimating $\tau$ to ca $1 \mathrm{~s}$ from observed reorientations from $\pi / 4$ to $3 \pi / 4$ rad (Eriksson \& Jonsson unpubl.), Eq. (14) yields an $L$ of about $1 \mu \mathrm{m}$. This shows that the centre of gravity and the centre of buoyancy have to be separated only by a short distance to produce a significant reorientation rate, and thus a negative geotaxic swimming behaviour.

\section{Swimming behaviour in shear flow}

We observed and quantified behaviour of competent larvae in a flume with a sedimentary bottom at 4 freestream velocities: $0,2,5$ and $10 \mathrm{~cm} \mathrm{~s}^{-1}$ (Table 2). In still water larvae swam upward interrupted by downward sinking and occasional periods of rest on the sediment surface, which often lasted from a few seconds to some minutes. This behavioural pattern changed remarkably when larvae were subjected to free-stream velocities of 5 and $10 \mathrm{~cm} \mathrm{~s}^{-1}$. In these treatments larvae slowly drifted in the streamwise direction just above the sediment surface. The $2 \mathrm{~cm} \mathrm{~s}^{-1}$ treatment yielded intermediate behavioural patterns where larvae drifted for shorter times but were often seen to swim upwards before again sinking to the bottom in the flume tank. Depending on water flow velocity ( 2 to $10 \mathrm{~cm} \mathrm{~s}^{-1}$ ), the drift velocity ranged between 0.45 and $1.6 \mathrm{~mm} \mathrm{~s}^{-1}$ (Table 2). Video recordings (from the side of the flume) of drifting larvae revealed that larvae actively swam, with their velum extended, while being transported in the near-bottom flow. Close observation in dissecting microscope $(12 \times)$ showed that larvae still moved in a helical manner although the motion was distorted by the superimposed flow and the occasional 
Table 2. Flow conditions and larval behaviour in a flume boundary-layer

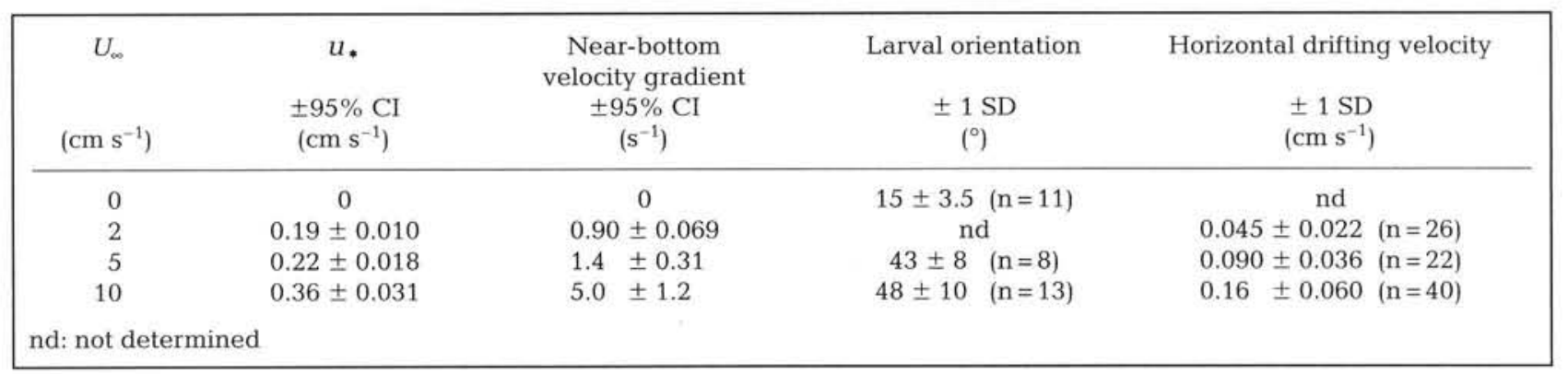

contacts with the bottom. At 5 and $10 \mathrm{~cm} \mathrm{~s}^{-1}$ larvae seemed to be trapped in the near-bottom flow, swimming and drifting very close above the bottom $(0$ to $0.5 \mathrm{~mm}$ ). Video recordings also showed that drifting larvae were significantly tilted with the velum pointing in the downstream direction (Table 2). When water flow in the flume ceased, larvae regained a body orientation with the velum pointing upwards, and began to swim upwards in helical paths interrupted by periods of sinking. When free-stream velocities exceeded $10 \mathrm{~cm} \mathrm{~s}^{-1}$ penetration of eddies into the viscous sub-layer became more frequent and larvae were often resuspended. At $15 \mathrm{~cm} \mathrm{~s}^{-1}$ larvae could not retain a smooth drift over the sediment surface but began to tumble in bed-load transport with frequent resuspension events.

The confinement of larvae to the near-bottom layer in faster flows is puzzling. It may be an active behaviour involving perception of the steep velocity gradient close to the sediment surface linked to adjustments of swimming activity. A slight problem with this hypothesis is that such a response would tend to prevent larvae from reaching the bottom when approaching from above. Our study was not designed to test this hypothesis and it remains an open question. However, below we suggest that a simpler, hydrodynamic mechanism may explain the observed nearbottom transport of larvae.

In still water the ciliary propulsion produced by the velum and the gravitational torque on the larval body, as discussed above, will cause the larva to swim upwards. However, when the larva approaches a bottom subjected to horizontal water flow and enters the boundary layer, the velocity gradient will impose a shear force acting over the larval body. This shear will induce a viscous drag torque, $T_{\text {visc }}$

$$
T_{\text {visc }}=4 \pi \mu a^{3}\left[\frac{\mathrm{d} u}{\mathrm{~d} z}-2 \omega\right]
$$

(Kessler 1986) where $\mathrm{d} u / \mathrm{d} z=$ the velocity gradient over the larval body (assumed to be spherical); and $\omega$ is the angular velocity of the body. The viscous torque,
$T_{\text {visc }}$ will oppose the gravitational torque, $T_{\text {grav }}$ (Eq. 11), and will compensate it when $\omega=0$. The stable equilibrium orientation is derived as

$$
\sin \Theta=\frac{3 \mu}{L \rho g} \frac{\mathrm{d} u}{\mathrm{~d} z}
$$

Assuming $L$ to be of the order of $1 \mu \mathrm{m}$, the equilibrium orientation in Eq. (16), shows that retention in the near-bottom flow ( $\Theta \geq \pi / 2$ rad) occurs when $\mathrm{d} u / \mathrm{d} z$ exceeds $3.5 \mathrm{~s}^{-1}$. Above this critical velocity gradient, $T_{\text {visc }}$ will everywhere exceed $T_{\text {grav }}$ and no equilibrium orientation is possible, causing the larvae to tumble over the bottom. Thus, although the larva shows a morphological negative geotaxis, a sufficiently high near-bottom shear will prevent the larva from swimming upwards and the larva is retained close to the bottom.

Eq. (16) assumes that larval motion is only translational without any rotational components. This is obviously not the case since larvae of Cerastoderma edule swim in helices, involving at least 2 degrees of rotational freedom. To analyze the effect of nearbottom shear velocity on a helical swimming behaviour a numerical model was used. By finite difference computer simulation, the gravitational and viscous torques (Eqs. 11 \& 15) were evaluated and added to the helical motion at each time step (0.001 s). An example of 2 simulated larval trajectories which differ in the nearbottom velocity gradient is presented in Fig. 4. The critical near-bottom velocity gradient, that will cause larvae to be trapped in the boundary-layer, is a function of $L$ and the roll, $\omega_{1}$, and pitch, $\omega_{2}$, rotational velocities. Critical velocity gradient is directly proportional to $L$ and increases asymptotically with $\omega_{1}$ (Fig. 5a, b). An increasing $\omega_{2}$ reduces critical velocity gradient and when $\omega_{2}$ is sufficiently large (for a given $\omega_{1}$ ) the gravitational force dominates the upward propulsive force and the larva remains on the bottom regardless of the velocity gradient (Fig. 5c). The simulations show that when $L$ is $1 \mu \mathrm{m}$ a velocity gradient of $2 \mathrm{~s}^{-1}$ is needed to prevent larvae from leaving the near-bottom region (Fig. 5a). This is close to the 
a

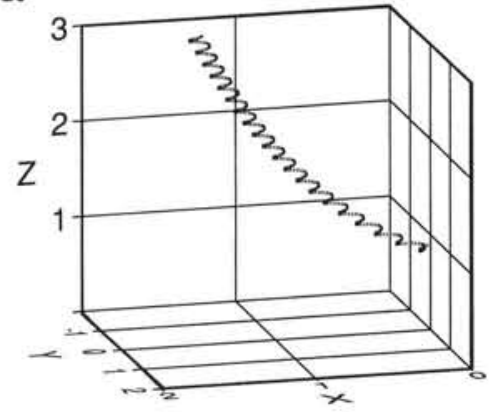

b

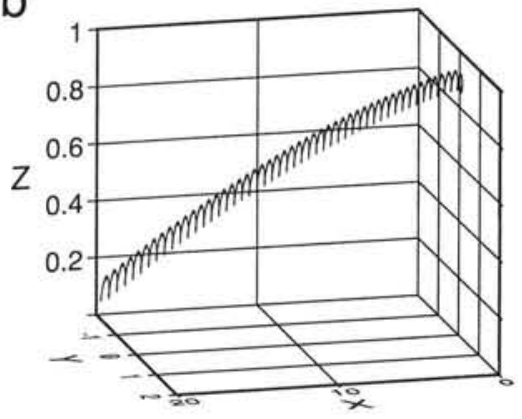

Fig. 4. Cerastoderma edule. Simulated swimming paths of larvae. Water flow is in the positive $x$-direction but, to condense the graphs, flow velocity is not added to the swimming movement. Scale units are in $\mathrm{cm}$. (a) Low near-bottom shear $\left(U_{\infty}=2 \mathrm{~cm} \mathrm{~s}^{-1}\right)$, (b) high near-bottom shear $\left(U_{\infty}=5 \mathrm{~cm} \mathrm{~s}^{-1}\right)$

velocity gradient found in the flume experiments at a free-stream velocity of $5 \mathrm{~cm} \mathrm{~s}^{-1}$ where near-bottom confinement became evident (Table 2). The lower critical velocity gradient necessary to confine larvae in the near-bottom region for helical swimming behaviour compared to non-rotational behaviour is probably due to the constant change of larval orientation through the pitch rotation $\left(\omega_{2}\right)$ which reduces the net effect of the geotaxic reorientation.

To our knowledge, the only study that shows similar observations of near-bottom confinement is the work by Pawlik et al. (1991) who observed bed-load transport of polychaete larvae in a flume-generated flow $\left(U_{\infty}=15 \mathrm{~cm} \mathrm{~s}^{-1}\right)$, where the larvae were observed to tumble along the bottom. The important question is whether such observations of near-bottom transport of larvae should be expected in the field. The flow velocities that induced near-bottom drift of larvae (5 to $15 \mathrm{~cm} \mathrm{~s}^{-1}$ ) in the present study are reported to be typical in the few studies of shallow soft bottoms where flow velocities have been measured in the field (Butman 1986, Vincent et al. 1988), although velocities may exceed $50 \mathrm{~cm} \mathrm{~s}^{-1}$ in areas with strong tidal currents (Fréchette et al. 1989). However, it is difficult to extrapolate the near-bottom drift of larvae presented
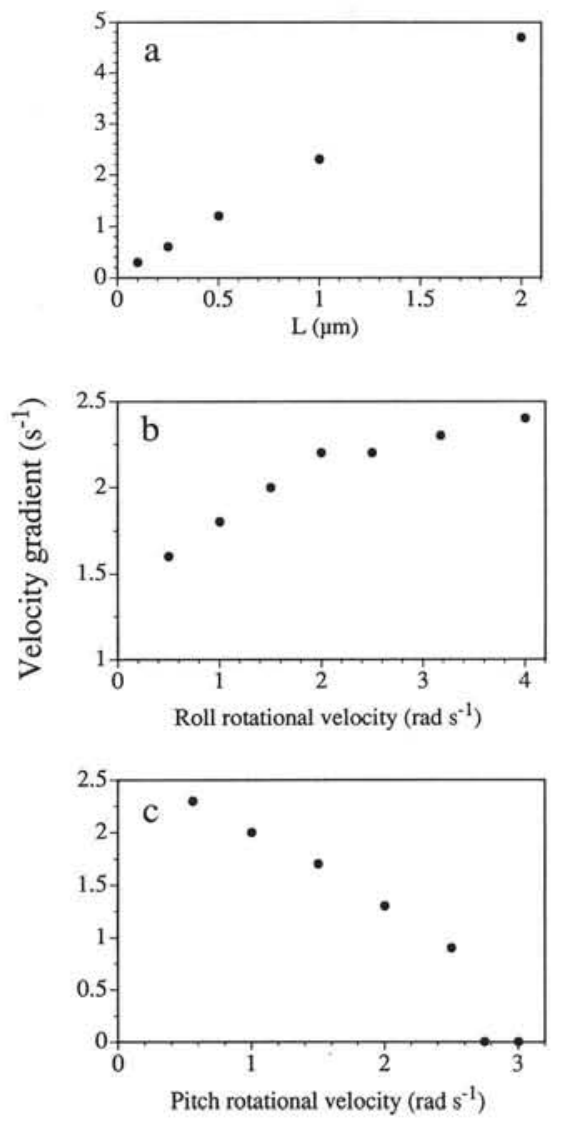

Fig. 5. Results from computer simulations showing how the critical velocity gradient that confines larvae in the nearbottom flow varies with: (a) the separation distance, $L$, between the centres of buoyancy and gravity $\left(\omega_{1}=3.2 \mathrm{rad} \mathrm{s}^{-1}\right.$, $\left.\omega_{2}=0.56 \mathrm{rad} \mathrm{s}^{-1}\right)$; (b) the roll rotational velocity, $\omega_{1}\left(\omega_{2}=\right.$ $0.56 \mathrm{rad} \mathrm{s}^{-1}, L=10^{-6} \mathrm{~m}$ ); (c) the pitch rotational velocity, $\omega_{2}\left(\omega_{1}=3.2 \mathrm{rad} \mathrm{s}^{-1}, L=10^{-6} \mathrm{~m}\right)$

here to field situations, where unsteady, oscillatory flows and complex topography will make the flow pattern much more complicated. Flow conditions in the field will probably only intermittently be similar to the steady unidirectional flow generated in our flume. If these intervals of flow that induce near-bottom drift are frequent events in the field, the observed drift of competent larvae in near-bottom flow may have farreaching consequences for the dynamics of settlement. The intervals of drift will greatly increase the encountered area of potential settlement sites and this behaviour may explain how substratum selectivity is accomplished in flowing water despite the constraints of larval motility (Butman et al. 1988). Previously, it has been suggested that selectivity of substrata in flowing water may be attained by a 'ballooning' or 'ping-pong' behaviour (Keough \& Downes 1982, Butman 1986, Butman et al. 1988) where settling larvae have the option either to stay at the site encountered or to swim 
upwards to be carried in the bottom current and settle at a new site. Although this behaviour may occur in many larvae, a slow drift close to the bottom allows more frequent sampling of the sediment surface where different cues may stimulate or inhibit final settlement (Butman 1987). Sampling may require direct contact with the substratum (Wilson 1968) and we observed that drifting larvae regularly $\left(1.2 \mathrm{~min}^{-1}, \mathrm{SD}=0.5\right.$, $\mathrm{n}=22, U_{\infty}=10 \mathrm{~cm} \mathrm{~s}^{-1}$ ) stopped swimming to rest on the bottom for 5 to $10 \mathrm{~s}$. However, the small distance $(<1 \mathrm{~mm})$ to the sediment and the location within the non-turbulent, viscous sublayer should also permit chemokinetic responses to diffusive substances (Crisp 1974, Dodds 1990).

While the possibility of substratum selection will be enhanced by near-bottom drift, the risk of predation by established suspension feeders may be maximized. Near-bottom drift will increase the exposure of larvae to suspension feeding predators with inhalant siphons or tentaculate structures. There may thus be a trade-off between the probability of successful settlement and mortality due to predation in the natural selection of larval morphology and behaviour.

Acknowledgements. The study was supported by the Swedish Natural Science Research Council through contract B-BU 1860-303 to P.R.J. and through contract B-BU 3294-303 to C.A. Additional support was provided to P.R.J., C.A. and M.L. by grants from the foundations of Magnus Bergvall, Helge Ax:son Johnson, Lars Hierta, Collianders and The Royal Academy of Science.

\section{LITERATURE CITED}

André, C., Rosenberg, R. (1991). Adult-larval interactions in the suspension-feeding bivalves Cerastoderma edule and Mya Arenaria. Mar. Ecol. Prog. Ser. 71: 227-234

Bayne, B. L. (1964). The responses of the larvae of Mytilus edulis L. to light and to gravity. Oikos 15: 162-174

Beukema, J. J. (1976). Biomass and species richness of the macrobenthic animals living on the tidal flats of the Dutch Wadden Sea. Neth. J. Sea Res. 10: 236-261

Butman, C. A. (1986). Larval settlement of soft-sediment invertebrates: some predictions based on an analysis of near-bottom velocity profiles. In: Nihoul, J. C. J. (ed.) Marine interface ecohydrodynamics. Elsevier, Amsterdam, 487-513

Butman, C. A. (1987). Larval settlement of soft-sediment invertebrates: the spatial scales of pattern explained by active habitat selection and the emerging rôle of hydrodynamical processes. Oceanogr. mar. Biol. Ann. Rev. 25: 113-165

Butman, C. A., Grassle, J. P., Webb, C. M. (1988). Substrate choices made by marine larvae settling in still water and in a flume flow. Nature, Lond. 333: 771-773

Chia, F.-S., Buckland-Nicks, J., Young, C. M. (1984). Locomotion of marine invertebrate larvae: a review. Can. J. Zool, 62: 1205-1222

Chia, F. S., Koss, R., Bickell, L. R. (1981). Fine structural study of the statocysts in the veliger larva of the nudibranch, Rostanga pulchra. Cell. Tissue Res. 214: 67-80

Cragg, S. M., Nott, J. A. (1977). The ultrastructure of the statocysts in the pediveliger larvae of Pecten maximus (L.) (Bivalvia). J. exp. mar. Biol. Ecol. 27: 23-36

Crenshaw, H. C. (1989a). The helical motion of microorganisms: a novel orientation mechanism. Ph.D. thesis, Duke University, Durham

Crenshaw, H. C. (1989b). Kinematics of helical motion of microorganisms capable of motion with four degrees of freedom. Biophys. J. 56: 1029-1035

Crisp, D. J. (1974). Factors influencing the settlement of marine invertebrate larvae. In: Grant, P. T., Mackie, A. M. (eds.) Chemoreception in marine organisms. Academic Press, London, p. 177-265

Dodds, W. K. (1990). Hydrodynamic constraints on evolution of chemically mediated interactions between aquatic organisms in unidirectional flows. J. Chem. Ecol. 16: $1417-1430$

Eckman, J. E. (1983). Hydrodynamic processes affecting benthic recruitment. Limnol. Oceanogr. 28: 241-257

Eckman, J. E. (1990). A model of passive settlement by planktonic larvae onto bottoms of differing roughness. Limnol. Oceanogr. 35: 887-901

Eckman, J. E., Savidge, W. B., Gross, T. F. (1990). Relationship between duration of cyprid attachment and drag forces associated with detachment of Balanus amphitrite cyprids. Mar. Biol. 107: 11-118

Fenchel, T., Jonsson, P. R. (1988). The functional biology of Strombidium sulcatum, a marine oligotrich ciliate (Ciliophora, oligotrichina). Mar. Ecol. Prog. Ser. 48: 1-15

Fréchette, M., Butman, C. H., Geyer, W. R. (1989). The importance of boundary-layer flows in supplying phytoplankton to the benthic suspension feeder, Mytilus edulis L. Limnol. Oceanogr. 34: 19-36

Happel, J., Brenner, H. (1983). Low Reynolds number hydrodynamics. Martinus Nijhoff Publishers, Dordrecht

Jonsson, P. R. (1989). Vertical distribution of planktonic ciliates - an experimental analysis of swimming behaviour. Mar. Ecol. Prog. Ser. 52: 39-53

Keough, M. J., Downes, B. J. (1982). Recruitment of marine invertebrates: the role of active larval choices and early mortality. Oecologia 54: 348-352

Kessler, J. O. (1986). The external dynamics of swimming micro-organisms. Prog. Phycol. Res. 4: 257-307

Lindegarth, M., Jonsson, P. R., André, C. (1991) Fluorescent microparticles: a new way of visualizing sedimentation and larval settlement. Limnol. Oceanogr. 36: 1471-1476

Luckenbach, M. W. (1984). Settlement and early postsettlement survival in the recruitment of Mulinia lateralis (Bivalvia). Mar. Ecol. Prog. Ser. 17: 245-250

Mann, R., Campos, B. M., Luchenbach, M. W. (1991). Swimming rate and responses of larvae of three mactrid bivalves to salinity discontinuities. Mar. Ecol. Prog. Ser. 68: $257-269$

Mann, R., Wolf, C. C. (1983). Swimming behavior of larvae of the ocean quahog Arctica islandica in response to pressure and temperature. Mar. Ecol. Prog. Ser. 13: 211-218

Moore, P. G. (1975). The role of habitat selection in determining the local distribution of animals in the sea. Mar. Behav. Physiol. 3: 97-100

Möller, P., Rosenberg, R. (1983). Recruitment, abundance and production of Mya arenaria and Cardium edule in marine shallow waters, western Sweden. Ophelia 22: 33-55

Nowell, A. R. M., Jumars, P. A. (1984). Flow environments of aquatic benthos. Ann. Rev. Ecol. Syst. 15: 303-328 
Pawlik, J. R., Butman, C. A., Starczak, V. R. (1991). Hydrodynamic facilitation of gregarious settlement of a reefbuilding tube worm. Science 251: 421-424

Pennington, J. T., Strathmann, R. R. (1990). Consequences of the calcite skeletons of planktonic echinoderm larvae for orientation, swiming, and shape. Biol. Bull. mar. biol. Lab., Woods Hole 179: 121-133

Petersen, C. G. L. (1918). The sea bottom and its production of fish foods; a survey of the work done in connection with valuation of Danish waters from 1883-1917. Rep. Dan. Biol. Stn 25: 1-62

Pires, A., Woollacott, R. M. (1983). A direct and active influence of gravity on the behavior of a marine invertebrate larva. Science 220: 731-733

Roberts, A. M. (1970). Geotaxis in motile micro-organisms. J. exp. Biol. 53: 687-699

Runnström, J. (1930). Zur Bewegungsphysiologie der Seeigellarve und anderer Planktonlarven. Z. vergl. Physiol. 11: $503-522$

This article was submitted to the editor
Schlichting, H. (1979). Boundary-layer theory. McGraw-Hill, New York

Sulkin, S. D. (1973). Depth regulation of crab larvae in the absence of light. J. exp. mar. Biol. Ecol. 13: 73-82

Sulkin, S. D. (1984). Behavioral basis of the depth regulation in the larvae of brachyuran crabs. Mar. Ecol. Prog. Ser. 15: $181-205$

Thorson, G. (1966). Some factors influencing the recruitment and establishment of marine benthic communities. Neth. J. Sea Res. 3: 267-293

Underwood, A. J., Fairweather, P. G. (1989). Supply-side ecology and benthic marine assemblages. Trends Ecol. Evol. 4: 16-20

Vincent, B., Desrosiers, G., Gratton, Y. (1988). Orientation of the infaunal bivalve Mya arenaria L. in relation to local current direction on a tidal flat. J. exp. mar. Biol. Ecol. 124: 205-214

Vogel, S. (1981). Life in moving fluids. Grant, Boston

Wilson, D. P. (1968). The settlement behaviour of the larvae of Sabellaria alveolata. J. mar. biol. Ass. U.K. 48: 387-435

Manuscript first received: May 2, 1991

Revised version accepted: December 2, 1991 